\title{
Analyzing Male Attractiveness Models from a Communicative Approach:
}

\author{
Socialization, Attraction, and Gender-based Violence. \\ Javier Díez-Palomar, Marta Capllonch, Emilia Aiello
}

Javier Díez-Palomar is Ramon y Cajal researcher in the Department of Science and Mathematics Education, at the University of Barcelona. He has been Fulbright Visitor Scholar in the CEMELA (Center for the Mathematics Education of Latinos/as), at the University of Arizona. Spanish representative in the International Commission for the Study and Improvement of Mathematics Teaching. He is actively involved in Learning Communities and in a New Masculinities association. Chief Editor of the Journal REDIMAT and Adults Learning Mathematics: An International Journal.

Address: University of Barcelona, Department of Science and Mathematics Education. Campus Mundet, Passeig de la Vall d'Hebron, 171. Edifici de Llevant, Planta 1, Despatx 15508035 Barcelona, Spain. Phone: +34 93403 5099E-mail: jdiezpalomar@ub.edu

Marta Capllonch is a Professor in the Department of Physical Education of the Faculty of Teacher Education at the University of Barcelona. Her main lines of research are on prevention and conflict resolution through physical education. She has been the main researcher of the study funded by the Spanish National Plan for R+D Play, Dialogue and Solve. Overcoming conflicts in physical education from the Dialogic Model. Design of a specific program for Learning Communities (2008-2011). She has also participated in other research projects about gender violence prevention, and training for gender violence prevention from the University of Barcelona.

Address: University of Barcelona, Department of Physical Education. Campus Mundet. Passeig de la Vall d'Hebron, 171. 08035 Barcelona, Spain. Phone: +34 93.403 5141. Email: mcapllonch@ub.edu

Emilia Aiello is a PhD Candidate at the Department of Sociology at the Autonomous University of Barcelona (UAB), and a Fellow at the Group of Ethnic Studies and Migration (GEDIME-UAB). Some of her research collaborations have been mainly in RTD projects such as INCLUD-ED. Strategies for Inclusion and Social Cohesion in Europe from Education, funded by the European Commission (RTD Integrated Project, 6 Framework Program, 2006-2011); DROM-IN. Roma immigration in Spain: the challenges of social inclusion and coexistence (Spanish RTD, 2009-2011), and TRANSROMA. Strategies of mobility, return and transnational practices among Romanian Roma (Spanish RTD, 20082011).

Address: Autonomous University of Barcelona. Department of Sociology. Edifici B Despatx B3-117. 08193 Bellaterra, Spain. Phone: +34.93 581 2406. E-mail: emilia.aiello@uab.cat 


\begin{abstract}
Although the analysis of male attractiveness models is key to shed light into the prevention of gender-based violence, it is not always easy to access to crucial information about these models. Research shows that inadequate data collection techniques can lead to reproducing superficial arguments confirming existing stereotypes instead of tackling with the real connections. Using communicative daily life stories and communicative focus groups, we take on the challenge of accessing to the existing models of male attractiveness' foundations. These techniques are used to collect data about the specific attractiveness models into which adolescents are socialized and their potential link to violence. We argue that the communicative orientation furthers the scientific understanding of the dominant traditional model of masculinity that socializes into gender-based violence and the new alternative model of masculinity that socializes into its overcoming. The use of communicative techniques is showed to empower participants to question their attractive preferences.
\end{abstract}

Keywords: Communicative techniques, Traditional masculinities, New alternative

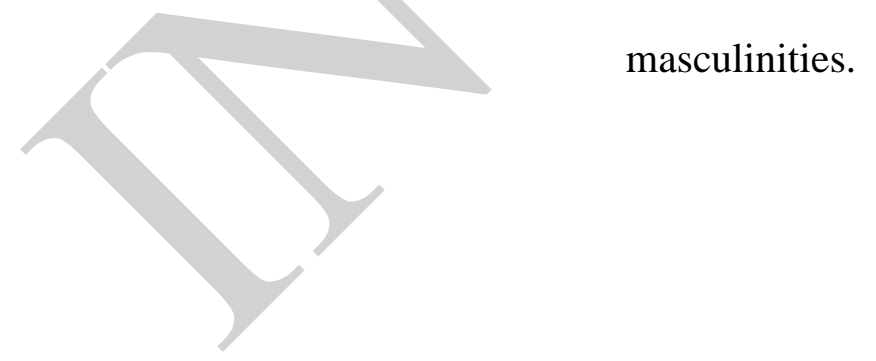




\section{Analyzing Male Attractiveness Models from a Communicative Approach: Socialization, Attraction, and Gender-based Violence}

Inadequate research techniques, and ways of using such techniques when analyzing social phenomena, can lead to biased analyses that reproduce superficial arguments and confirm existing stereotypes rather than dismantling them. This situation has often arisen in research on gender-based violence (hereinafter, GBV). Due to the utilization of ill-suited research techniques, the root causes of GBV have not always been well identified, and the means established to end or prevent GBV at a practical level have not been the appropriate ones. The communicative methodology of research (hereinafter, CM) sheds new light on studies about GBV (Aubert, Melgar, \& Valls, 2011). In particular, communicative studies have enabled deeper examination of the models of male attractiveness into which adolescents are socialized and the identification of links between these models and GBV. Thus, the CM has proven to be effective in identifying the influence of socialization to explain sexual attraction.

Throughout this article, we provide examples of real situations that occurred with adolescents while conducting communicative daily life stories (hereinafter, CDLS) and communicative focus groups (hereinafter, $\mathrm{CFG)}$ for the study Education in values for the prevention of gender-based violence in high school education (Valls, 2004-2005). Although we are aware of the multilayered complexity of reality, we present the results related to two of the three ideal types of male attractiveness models theorized by Flecha, Puigvert, and Rios (2013): ${ }^{\mathrm{i}}$ the dominant traditional model of masculinity as the model that contribute to perpetuate GBV, and the new alternative model of masculinity as the model that allows its prevention and leads to its overcoming. In the following sections, we show that CDLS and 
CFG represent a step beyond traditional data collection techniques by reinterpreting the experiences of the sexual-affective relationships of the researched subjects through an intersubjective and egalitarian dialogue that examines the aspects that are most meaningful from the experience of the subjects themselves.

\section{Contributions about models of masculinity, GBV, and research methods}

The study of the models of masculinity and their relationship to gender inequalities and GBV has become a relevant topic of research within the field of men's studies and gender studies. In the late 1980s, Connell (1987) was one of the first scholars to theorize the concept of hegemonic masculinity based on the domination of a particular model of male behavior that relies on a pattern of practices, a set of identity values, and social expectations of how a man should be to allow the dominance of men over women and to reinforce existing inequalities. The hegemonic masculinity model was studied by other authors as a driver of diverse social problems (Ullah \& Ali, 2012), including GBV (Connell \& Messerschimdt, 2005; Kimmel, 1996, 2000). Connell and Messerschimdt (2005) emphasizes, however, that not all men belonging to hegemonic masculinity are violent: "Hegemony did not mean violence, although it could be supported by force; it meant ascendancy achieved through culture, institutions, and persuasion" (p. 832).

Although there is considerable agreement in the scientific community that the aforementioned theories on hegemonic masculinity have correctly identified the reasons underlying gender-unequal relations, less agreement exists regarding how these theories have addressed GBV. These theories have not considered some important elements that other research has suggested are essential to understand the roots of GBV. In this sense, many qualitative studies of GBV have provided evidence of the close relationship between 
the model of attractiveness and the process of socialization (Flecha, Rios, \& Puigvert, 2013; Padrós, 2006-2007). These studies noted that in the case of heterosexual relationships, the internalized link between sexual attraction and violence leads to exclusionary (understood as negative) male models as one of the main causes of GBV. Particularly in the case of adolescents, family, school, and, especially, the mass media and peer groups are main agents of socialization and (occasionally unwittingly) encourage the association of love with violence, ultimately promoting attraction toward harmful persons (Padrós, Aubert, \& Melgar, 2010).

Researches about models of masculinity and GBV have been carried out using different methods, including quantitative, qualitative, and mixed methods. Related to this, Hearn et al. (2013) when studying male violence emphasize, however, that "there is a need to go beyond quantitative measures that are primarily descriptive and lack in-depth analysis. There is a need to build foundations for culturally-sensitive studies” (p. 99). In this regard, several authors have attempted to overcome the limitations of quantitative methodologies based on the distance between the researcher and the researched subject. Consistently, Aubert, Melgar, and Valls (2011) in their analysis of models of masculinity and gender violence among teenagers go a step beyond and show the relevance of implementing methodologies that allow the researcher to fully capture subjects' interpretations of their attractiveness model. With this, the authors refer to methodologies that enable to research on how these models are formed through the subjects' interactions as it is the communicative approach. Additionally, McCarry (2012) in her multimethodology study about young people's experiences of violence in their intimate relationships contribute to some strategies used to include the voices of the researched subjects at the various stages of the research process, such as the creation of an Advisory 
Group aimed at advising the research team about the design of the research tools, the fieldwork process, the data analysis, etc.

In the communicative approach, the CDLS and the CFG allow the study participants, in dialogue with the researcher, to critically reflect on male attractiveness models, the choices of their affective relations, and the ways in which these are influenced by interactions (Aubert, Melgar, \& Valls, 2011). This approach has been a key methodological tool for the meta-research conducted by Flecha, Puigvert, and Rios (2013), who have drawn upon results of communicative investigations to go beyond traditional conceptions of hegemonic masculinity for a deeper analysis of male attractiveness models, particularly how their correct mapping and understanding can lead to or prevent GVB. Thus, these authors differentiate between the dominant traditional masculinity, the oppressed traditional masculinity, and the model of new alternative masculinities. They state that the first two models can contribute to the reproduction of violence against women, whereas the third model helps to its prevention and overcoming. Those new alternative masculinities can transform the traditional models in favor of more egalitarian relationships. According to the authors, men belonging to the latter model have at least three main characteristics: they are self-confident; they use courage as a strategy to confront negative attitudes held by the dominant traditional masculinities; and they explicitly reject the double standard (p. 102-103). Thus, the new alternative masculinities are associated with attractiveness and equality; they are desired while they are actively engaged in the fight against GBV.

Research has paid little attention to the most appropriate data collection techniques to investigate male attractiveness models, neglecting the possibility that their correct scientific analysis may contribute to preventing and ending GBV. This article aims to 
overcome this gap by demonstrating how the use of CDLS and CFG as data collection techniques that, due to their communicative dimension, allow examination beyond traditional conceptions of masculinities and thus further scientific understanding of the dominant traditional model of masculinity, which socializes into GBV, and the new alternative model of masculinity, which socializes into overcoming it.

\section{Methodology}

The findings we report here emerge from a study entitled, "Education in values for the prevention of gender-based violence in high school education" (Valls, 2004-2005). The aim of the study was to identify and analyze the values that were present in attractiveness models, the values that people considered attractive have, and also the adolescents' preferences when establishing sexual-affective relationships. As regards the fieldwork, more than 50 male and female high school students between the ages of 12 and 16 years old of different ethnic backgrounds were selected. The study chose this 12-16 age range because this is when teenagers are already acquainted the knowledge, values, and basic competences relevant to establishing sexual and affective relationships. Therefore, subjects at the beginning of this learning phase can engage in a critical reflection process about their preferences regarding the persons they like and to whom they are attracted to. A reflective process that opens up the possibility to choose those partners who would made possible to have satisfying, passionate and free of violence relationships. Data collection consisted of seven communicative focus groups (three with girls, two with boys, and two with both, each CFG with approximately six participants) and ten CDLS (five with girls and five with boys) were conducted. 
It should be noted that for this article it have been carefully selected from the entire fieldwork those examples of CDLS and CFG which are most illustrative of the relation between male attractiveness models, socialization and GBV.

For the data analysis, all information collected was transcribed and analyzed according to an analytical grid that was created ad-hoc for the study. The grid was structured around eight main analytical categories related to the project's aims: interactions; girls' voices regarding girls and boys; boys' voices regarding girls and boys; characteristics of friends; characteristics of the adolescents' sexual-affective relationships; definitions of violence expressed by adolescents; media and other institutions; and other aspects. First, all relevant information was selected and organized on the basis of this grid. Once the information was classified in these categories, data was analyzed according to the exclusionary/transformative dimensions in order to identify the values that adolescents expressed in their narratives through dialogue about their sexual-affective relationships. Because of the sensitive issues covered by study, a full explanation of the research was provided to all study participants and consent and assent forms were appropriately gathered, guaranteeing their intimacy and confidentiality.

\section{Communicative daily life stories with adolescents: reflecting on intimacy}

The use of CDLS has demonstrated great utility in studying male models of attractiveness because it allows for the examination of complex aspects that are difficult to access through traditional research techniques. For instance, in the following two examples of CDLS, it can be observed that each of the girls engages in critical reflection about the influence of her previous sexual-affective relationship on her present preferences as well as her reputation. In particular, many girls realized that their past contributed to themselves to 
be seen as more or less attractive in the present. The CDLS allow us to go even further by suggesting that past sexual-affective relationships have an opposite effect on boys and girls:

\begin{abstract}
Alba: Each time a guy hooks up with a girl, he is more successful; on the contrary, the girls don't, they call you "bitch" or something (Valls, 2004-2005).
\end{abstract}

Judit: The guys, when they get together, say I have screwed this one, and I have been with that one. On the contrary, we, we don't make fun of having been with many, but we keep it to ourselves (Valls, 2004-2005).

A major difference between traditional daily life stories and communicative ones is the location of the interpretative function of the action. In the CDLS, the interpretation is conducted by the researcher together with the study participant. In this sense, each of the protagonists in the CDLS above (Alba and Judit) is also dialogically reinterpreting her own reality. In their CDLS, many of the study participants began to share their real feelings about having been with boys who, despite being considered attractive in their high school, they did not treat them well. This was the case of Judit, who felt deeply cheated. In the CDLS she revealed that when she first had sex with Sergio, she was expecting to be his girlfriend the next day. Judit had dreamed about this. She bragged to her girlfriends that she had hooked up with Sergio. However, she felt sad because it did not happen as she hoped; Sergio only wanted to have sex with her and nothing else. He did not even say hello to her when they met at the high school the next day. It was through the CDLS that Judit opened up, moving beyond what she was telling her friends (she maintained the story of being very proud of having been with Sergio although she deeply regretted it). Judit also realized how this affair affected her reputation among other boys, whereas Sergio's reputation remained 
unchanged or even improved among the girls. Researchers engaged in a critical conversation with Judit sharing with her what their study says about the male models of attractiveness, and the role played of socialization into it.

Due to its communicative approach, the CDLS breaks with the hierarchical interpretation that has traditionally existed between the researcher and the researched subject. The CDLS includes an intersubjective dialogue in which both parts have something to contribute and to learn from each other. In this sense, the atmosphere of trust that is generated in the development of the CDLS allows research on GBV among adolescents to progress, allowing the subjects to identify their own contributions, such as what they perceptions about a good relationship based on passion, trust, or love. One among many examples was found in Kate's CDLS. The participant insisted that she had given up her dream of finding her prince charming, as if she had never desired it. However, in the course of the conversation, Kate ended up recognizing that it was due to her negative past experiences. First, she strongly emphasized that those who fall in love and have a "perfect" relationship are not honest, as if it was impossible to have one. In her story, she recognized that it was not that she did not care, but on the contrary, all her past relationships were initiated with the hope to be dream stories. However, nearly all of them turned to be with boys who were looking down to her, being aggressive in some occasions. Through her engagement with the researchers and after much discussion, she recovered her trust in boys, relationships, and love, as she realize and described her ideal story:

Interviewer: And the ideal story for your relationship...how would it be?

Kate: The ideal story? ...hmm...one in which passion and confidence with him never end. Interviewer: And the main values that this relationship would need to have? Beyond these? Or if they ...you have said certain values...imagine we place them in order...which ones would be the first ones or the most important ones...to keep this relationship? 
Kate: First the love...because otherwise...well, that we love each other. (Valls, 2004-2005)

As showed in this exchange, the use of CDLS allows for a deepening of the examination of adolescents' values and feelings about their ideal relationships. This atmosphere of proximity between the researcher and the researched subject not only sheds light on topics as personal and complex as love, ideals, and intimate relationships but also makes it possible to connect these stories to international scientific knowledge about preventing GBV. With regard to the story obtained through this particular CDLS, it is understood that the love relationship Kate expects to have is not only egalitarian and free of violence but also full of passion and attraction. However, this was not her initial reaction, her participation in the CDLS made possible to recover her child dreams. The type of relationship that she describes is clearly opposed to the hegemonic masculinity and the dominant traditional masculinity, it seeks the new alternative masculinity model.

\section{Communicative focus groups with adolescents as spaces of dialogue and reflection}

In the present study, CFGs seryed to collect data that contribute to dismantle extended misunderstandings of male models of attractiveness. In doing so, examples of celebrities were used. The main goal was to facilitate a discussion of the different elements that define the dominant traditional male model versus the oppressed and the new alternative masculinity models.

The main argument provided by Carol, Sarah, and Jenny to support the idea that Johnny Castle (the actor Patrick Swayze), the protagonist of the film Dirty Dancing, was that the character behaved violent following the hegemonic model of masculinity was his "macho attitude" and his dominant character in the dance. This debate arose during a CFG 
conducted with several adolescents while discussing what they considered the main traits of an egalitarian man and the famous main characters of films they believed fit this model.

When the researcher (a 35-year-old woman) who was moderating the CFG suggested that, according to recent scientific literature on masculinity and gender studies, Johnny Castle fit the model, Carol, Sarah, and Jenny energetically opposed this view. According to the girls, a "sexy" man like him could not be egalitarian and good. However, when the facilitator asked them about the character behaving violently, they could not provide a single instance of violence in the film. After one hour of dialogue and discussions of concrete situations and scenes, the researcher and the CFG participants agreed and observed together that Castle actually united within himself the characteristics of a man who belonged to the new alternative masculinity model: for example, he was attractive, egalitarian with Baby (the main actress of the film), and a good friend. If the analysis of the character had been performed through a traditional focus group, the conclusion would likely have been the opposite. However, the contrast with what the scientific community has already showed about the phenomena brought new lights into the discussion. Some of the arguments that the adolescents provided in the debate, such as "He dominates in the dance, he is physically strong, and he looks very dominant and protective" were contrasted in the CFG, leading to an exciting debate about relevant issues that helped all of the participants change their initial understandings of what the different masculinity models involved.

As observed in the previous example, the CFG gathers people with different perspectives and opinions who have lived a wide range of experiences with the aim of obtaining a collective interpretation of reality through the contributions of all participants (Puigvert, Christou, \& Holford, 2012). What it is important in a CFG is that opinions are measured according to the value of the arguments, not the speaker's position of power 
(Habermas, 1984). Thus, in the CFG, the role of the researcher is to motivate the participants of the group to engage in the debate and to bring their arguments - their lifeworld. Hence, researcher is also in charge of bringing into the discussion the accumulated scientific knowledge on the topic. This is a core characteristic of the communicative methodology that make it differ from other methodologies such as the traditional Action Research (Reason \& Bradbury, 2001), or other more innovative methodological approaches as the Participatory Action Synthesis (Wimpenny \& Maggi Savin-Baden, 2012).

Another key criterion to obtain a good result in the CFG, in addition to a comfortable environment, is that the participants are familiar with one another. Therefore, it is conducted with natural groups rather than ad hoc ones. Sufficient levels of trust allow the participants to dialogue about their feelings and personal experiences regarding their own sexual-affective relationships or even situations of GBV they have experienced. This is clearly illustrated in the example provided below obtained in a mixed CFG: the boys' views about the girls' sexual preferences for men differ greatly:

Anne: the majority of girls look for the cocky ones. They don't like the more quiet guys. This would be easier, that they give them a thrill (...).

Michael: No, but the girls like that. I think that, I am realizing more and more, that they don't like to be treated nicely.

Rebecca: No, you're wrong.

Michael: Sometimes they talk nastily to them in front of everyone to be cocky and, I don't know, weird stuff.

David: And the girl stays with him...

Interviewer: And do you think that there are more and more girls like that?

Michael: Yes, I think so. However, they, I think they like that. (Valls, 2004-2005) 
Due to its argumentative nature, CFG allows the different opinions of the participants to be contrasted and facilitates the examination of individual and collective subjectivity (Aubert, Melgar, \& Valls, 2011). Researchers can examine the social nature of contradictions and feelings related to the teenagers' preferences with regard to emotions, love, and sexual relationships. Consequently, communicative techniques enable the analysis of how attraction to men and to relationships that can result in situations of GBV do not always occur unwittingly, but have a social origin: socialization in a violent male model of attractiveness. This phenomenon is evidenced in the following quote:

Jane: (...) She'll know he's a bastard, and she will be with him

Liz: He's the typical womanizer that, woow!! You see him and you say, "I wanna be with him", and then you are with him and you think you'll change him and no...

Jane: No, you think that you'll change him.

Batty: You don’t want to change him, you know...

Liz: I think we are stupid because I am with a guy who is a bastard and he leaves me for another, and I will do everything possible to be with him, even if he leaves me afterwards for another...However, I don't think that I will change him; it is what I like and that's it, and that's why I do it (Valls, 2004-2005).

On many occasions, through participation in $\mathrm{CFG}$, study participants began to deeply question their preferences and choices. Through dialogue and with the guidance of the moderator, many girls realized they were attracted to violent men because this was what they had been exposed to. This realization did not leave them disempowered, as in the same way how they have internalized this model, it can be done otherwise. The girls were motivated to search for new relationships that would fulfill their initial romantic dreams. At the end of their participation, many of the subjects were grateful to the research team because these discussions were a turning point in their lives. 


\section{Conclusions}

The use of CDLS and CFG enable in-depth analyses of the models of attractiveness into which adolescents are socialized, including the new alternative masculinity model or the dominant traditional masculinity model, among many others. These data collection techniques allow for the exploration of the sentiments and personal experiences of the adolescents in relation to their sexual-affective relationships, establishing clear links between their past socialization and their present attraction. Thus, the CDLS and the CFG techniques enable deeper examination of the complexities of the different types of male models of attractiveness and their relation to GBV. At the same time, they raise key issues and debates, such as what an "ideal love story" involves, who the "bastards" are or why the "typical womanizers will never be able to change". These are debates that equip the adolescents with important clues to reflect on their own sexual-affective relationships and to search for violence-free and fulfilling relationships in which they can be equal, respected, and free to decide.

Critical reflection and profound debates will be achieved when dialogic spaces such as the ones enabled by the use of CDLS and the CFG are created. This requires scientific knowledge from the international community on gender violence to be brought together and contrasted with the lifeworlds and experiences of adolescents, teachers, and other members of the broader educational community. Consequently, the CDLS and CFG can become spaces for personal and collective transformation because when intimate issues are sincerely debated, the foundations of violent relationships can be questioned and "true love relationships" can be empowered. 


\section{References}

Aubert, A., Melgar, P., \& Valls, R. (2011). Communicative daily life stories and focus groups: proposals for overcoming gender violence among teenagers. Qualitative Inquiry, 17 (3), 295-303. doi: 10.1177/1077800410397808

Connell, R.W. (1987). Gender and power. Sydney: Allen and Unwin.

Connell, R. W. \& Messerschimdt, J. (2005). Hegemonic masculinity. Rethinking the concept. Gender Society, 19(6), 829-859. doi: 10.1177/0891243205278639

Flecha, R., Puigvert, L., \& Rios, O. (2013). The new masculinities and the overcoming of gender violence. International and Multidisciplinary Journal of Social Sciences, 2(1), 88-113. doi:10.4471/rimcis.2013.14

Habermas, J. (1984). The theory of communicative action. Vol.1. Reason and the rationalization of society. Boston: Beacon Press.

Hearn, J., Novikova, N., Pringle, K., Šmídová, I., Jyrkinen, M., Iovanni, L., \& Wojtaszek, M. (2013). Studying men's violences: Some key methodological principles in developing a European research framework. Masculinities and Social Change, 2(1), 82115. doi:10.4471/MCS.2013.22

Kimmel, M. (1996). Manhood in America: A cultural history. New York: Free Press.

Kimmel, M. (2000). The gendered society. NY: Oxford University Press.

McCarry, M. (2012). Who benefits? A critical reflection of children and young people's participation in sensitive research. International Journal of Social Research Methodology, 15(1), 55-68. doi: 10.1080/13645579.2011.568196

Padrós, M. (2006-2007). Models d'atracció dels i les adolescents. Contribucions des de la socialització preventiva de la violència de gènere [Adolescents' models of attraction. 
Contributions from the preventive socialization against gender violence]. Barcelona, Spain: Catalan Institute for Women. Catalan Goverment.

Padrós, M., Aubert, A. \& Melgar, P. (2010). Modelos de atracción de los y las adolescentes. Contribuciones desde la socialización preventiva de la violencia de género. Revista Interuniversitaria de Pedagogía Social, (17), 73-82. Retrieved from http://www.uned.es/pedagogiasocial.revistainteruniversitaria/pdfs/02\%20\%2017/05_padros.pdf

Puigvert, L., Christou, M., \& Holdford, J. (2012). Critical Communicative Methodology: Including vulnerables voices in research through dialogue. Cambridge Journal of Education, 42(4): 513-526. doi: 10.1080/0305764X.2012.733341

Reason, P. \& Bradbury, H., (Ed.). (2001). The SAGE Handbook of Action Research. Participative Inquiry and Practice. (1st ed.). London: Sage.

Valls, R. (2004-2005). Educació en valors per a la socialització preventiva de la violència de gènere als IES. [Education in values for the prevention of gender-based violence in high school education]. Barcelona, Spain: Department of Universities, Research, and Information Society, Catalan Government.

Ullah, H. \& Ali, J. (2012). Male hegemony through education: Construction of gendered identities. Multidisciplinary Journal of Gender Studies, 1(3), 215-242. doi:10.4471/generos.2012.11

Wimpenny, K. \& Savin-Baden, M. (2012). Exploring and implementing participatory action synthesis. Qualitative Inquiry, 18(8), 689-698. doi: 10.1177/1077800412452854

\footnotetext{
i The third model included in these authors' ideal typology is "oppressed traditional masculinity", characterized by non-sexist and "good" men who, in contrast to the new alternative masculinities, do not make themselves worthy with girls; therefore, their attitude does not contribute to overcoming GBV.
} 